\title{
Microstructure and mechanical properties of wire + arc additively manufactured 2024 aluminum alloy components: as-deposited and post heat- treated
}

Zewu Qi ${ }^{\text {a }}$, Bojin Qi ${ }^{\text {a, }}$, Baoqiang Cong ${ }^{\text {a, }}{ }^{*}$, Hongye Sun ${ }^{\text {a }}$, Gang Zhao ${ }^{\text {a }}$, Jialuo Ding ${ }^{\text {b }}$

a School of Mechanical Engineering and Automation, Beihang University, Beijing 100191, P.R. China

${ }^{\mathrm{b}}$ Welding Engineering and Laser Processing Centre, Cranfield University, Cranfield, MK430AL, UK

\begin{abstract}
Restricted by the type of commercial aluminum wire, 2024 aluminum alloy cannot be built through conventional single wire + arc additive manufacturing technology. By simultaneously feeding two wires (ER2319 and ER5087) and adjusting the wire feed speed, 2024 aluminum alloy deposits can be achieved with double - wire + arc additive manufacturing process. Heat treatment procedures (solution + natural/artificial aging) were conducted for further improving the properties. The microstructure and mechanical properties of as-deposited and heat-treated 2024 aluminum alloy deposits were tested and analyzed. The microstructure differed in different conditions. Obvious dendrite morphology in as-deposited condition disappeared after heat treatment, and the phases turned to be $\alpha-\mathrm{Al}+\mathrm{Al}_{2} \mathrm{Cu}$ from $\alpha-\mathrm{Al}+\mathrm{Al}_{2} \mathrm{Cu}+\mathrm{Al}_{2} \mathrm{CuMg}$. After heat treatment, layer distributing characteristics of the phases became obvious. Post-deposition heat treatment can improve the micro hardness, strength and horizontal elongation of WAAM 2024 aluminum alloy deposits. The elongation along vertical direction decreased.
\end{abstract}

Keywords wire + arc additive manufacturing; 2024 aluminum alloy; as-deposited; heat treatment; microstructure; mechanical property

\section{Introduction}

Additive manufacturing (AM) technique is raised up for directly fabricating components by adding materials, instead of removing materials from a block in traditional machining process. AM attracts more and more interests for its immanent advantages of saving lead time and material [1,2]. Wire + arc additive manufacturing (WAAM), one of AM techniques, employs arc as the heat source

\footnotetext{
* Corresponding author.

E-mail address: qbj@buaa.edu.cn (B. Qi); congbq@buaa.edu.cn (B. Cong).
} 
melting and depositing the filler wire along the designed path layer-by-layer. WAAM stands up from different AM techniques due to the benefits of producing large scale metallic structure, high platform flexibility and depositing rate, and low material and equipment cost [3]. It has been proved to be possible to adopt WAAM process to produce large metallic components [4].

2xxx series high strength aluminum alloys have been widely applied into aerospace field for the high strength to weight ratio and excellent mechanical properties. Fabricating high strength aluminum alloy structures with WAAM technique attracts interests and requirements from researchers and aerospace industries. Bai et al. [5] produced 2219 aluminum alloy components with GTA-WAAM process, and studied the mechanical properties. Cong et al. [6] considered the effects of heat input, environmental atmosphere, and wire feed speed on porosity in 2219 aluminum alloy deposits with AC-GTAW process, and found heat input was the most important factor affecting the porosity defect. As illustrated by Cong et al. [7], the porosity of WAAM aluminum alloys can be prominently affected by the arc mode in cold metal transfer (CMT) process, and CMT pulse advanced arc mode was proved to be the most applicable process for effectively controlling the porosity. Cong et al. [8] further found the depositing path and CMT arc mode can influence the porosity, microstructure and mechanical properties of WAAM 2219 aluminum alloys. Gu et al. [9, 10] studied the microstructure and mechanical properties the WAAM 2219 aluminum alloys with CMT process, and further pointed out inter-layer cold working can improve the properties and eliminate pores in the deposits.

2024 aluminum alloy, one of the 2xxx series aluminum alloys, is a representative ternary Al$\mathrm{Cu}-\mathrm{Mg}$ aluminum alloy, which has been widely used in missile and airscrew for space vehicles. However, it cannot be directly produced through conventional single wire + arc additive manufacturing process, as there is no kind of aluminum wire matching the element compositions of 2024 aluminum alloy. Qi et al. [11] introduced a double wire device to achieve double - wire + arc additive manufacturing (D-WAAM) process, through which ternary $\mathrm{Al}-\mathrm{Cu}-\mathrm{Mg}$ aluminum alloys can be built with binary $\mathrm{Al}-6.3 \mathrm{Cu}$ and $\mathrm{Al}-5 \mathrm{Mg}$ wires, and the element composition can be regulated by adjusting the wire feed speed. This research makes it possible to build 2024 aluminum alloy components through D-WAAM process with conventional wires. However, the properties of asdeposited 2024 aluminum alloy are comparatively low and cannot meet the applying requirements.

Heat treatment procedures have been proved to improve the mechanical properties of $2 \mathrm{xxx}$ series aluminum alloy welds [12-14]. Solution and aging treatment are widely employed to 
strengthen the mechanical properties. Heat treatment procedures are also recently employed to improve the properties of WAAM 2xxx series aluminum alloy components. Gu et al [9] introduced solution treatment + artificial aging to process the WAAM 2219 aluminum alloy, finding the strength properties can be significantly enhanced. Bai et al. [15] carried out an especial heat treatment to process the 2219 aluminum alloy deposits and reported the ultimate strength was improved. Qi et al [16] adopted solution + natural aging (with different solution treatment temperature) to treat WAAM 2024 aluminum alloy, and briefly studied the development tendency of properties, finding the properties presented an increasing trend with higher solution treatment temperature, however, the research results are not comprehensive enough. More systematic research is needed.

In this paper, WAAM 2024 aluminum alloy components were built. Heat treatment procedures (solution treatment + natural/artificial aging) were conducted to process the components. The microstructure and mechanical properties of as-deposited and post heat-treated components were comprehensively investigated.

\section{Experimental procedures}

\subsection{Materials}

ER2319 (Al-6.3 wt\% Cu) and ER5087 (Al-5 wt\% Mg) (both 1.2mm in diameter) were chosen as the filler wires, and AA2024 plate $(320 \mathrm{~mm} \times 150 \mathrm{~mm} \times 12 \mathrm{~mm}$ in dimension) as the substrate. The nominal composition of the wires and substrate is revealed in Table 1.

\section{Table 1}

Composition of ER2319, ER5087 wire, AA2024 substrate and WAAM deposit

\begin{tabular}{|c|c|c|c|c|c|c|c|c|c|c|}
\hline \multirow{2}{*}{ Alloys } & & $\rho$ & \multicolumn{8}{|c|}{ Composition (wt. \%) } \\
\hline & & $\mathrm{g} / \mathrm{cm}^{3}$ & $\mathrm{Cu}$ & $\mathrm{Mg}$ & $\mathrm{Si}$ & $\mathrm{Mn}$ & $\mathrm{Zr}$ & $\mathrm{Fe}$ & $\mathrm{Ti}$ & $\mathrm{Al}$ \\
\hline ER2319 & & 2.77 & 6.3 & - & 0.04 & 0.28 & 0.19 & 0.1 & 0.145 & Bal. \\
\hline ER5087 & & 2.66 & - & 5.05 & 0.05 & 0.74 & 0.12 & 0.1 & 0.114 & Bal. \\
\hline AA2024 & & 2.75 & 4.4 & 1.5 & 0.5 & 0.6 & - & 0.5 & 0.20 & Bal. \\
\hline WAAM & Calculated & - & 4.44 & 1.49 & 0.04 & 0.42 & 0.17 & 0.1 & 0.14 & Bal. \\
\hline deposit & Tested & - & 4.36 & 1.54 & - & 0.52 & - & - & - & $\mathrm{Bal}$ \\
\hline
\end{tabular}

\subsection{WAAM process}


The additive manufacturing process was carried out with double - wire + arc additive manufacturing (D-WAAM) system [11], by which thin wall components (single-pass and multilayers, $280 \mathrm{~mm} \times 105 \mathrm{~mm} \times 7 \mathrm{~mm}$ in dimension) were produced, as shown in Fig. 1. The processing parameters, as shown in Table 2, were kept constant for all the deposits. In order to achieve similar element composition of AA2024 aluminum alloy, the wire feed speed (WFS) of ER2319 and ER5087 was set through the equation

$$
E=\frac{\sum W F S_{i} D_{i}^{2} \rho_{i} E_{x}}{\sum W F S_{i} D_{i}^{2} \rho_{i}}
$$

where $\mathrm{E}_{x}$ is the content of the element $(x)$ in a certain wire, $\operatorname{WFS}_{i}(i=1,2)$ is the wire feed speed, $\mathrm{D}_{i}$ and $\rho_{i}$ is the diameter and density of the wire, respectively. The calculated composition results and tested composition results of main elements with inductively coupled plasma optical emission spectrometer (ICP-OES, Varian 715-ES) were shown in Table 1. As the composition of main elements in WAAM deposit is similar to the one in AA2024 aluminum alloy, the additively manufactured material will be referred as WAAM 2024 alloy or 2024 deposit in this paper.

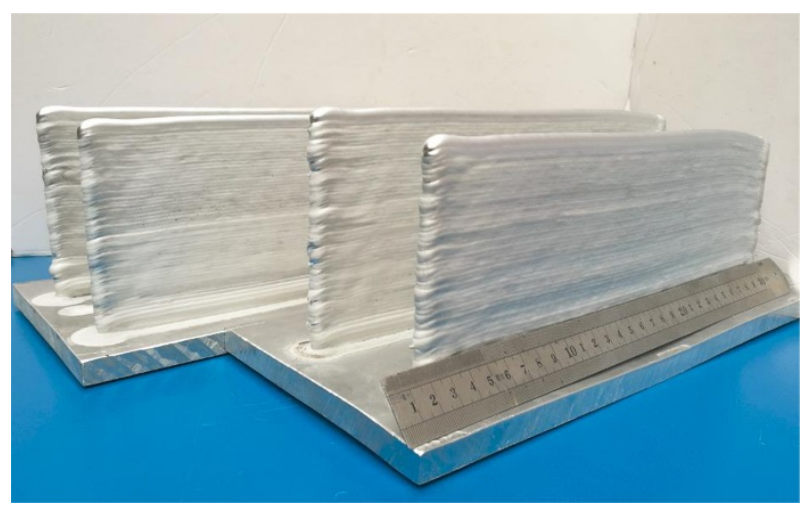

Fig. 1. WAAM thin wall components

Table 2

WAAM processing parameters

\begin{tabular}{llc}
\hline & Current (A) & 120 \\
VP-GTAW arc & Frequency $(\mathrm{Hz})$ & 100 \\
& DCEN:DCEP & $4: 1$ \\
& ER2319 & 2.4 \\
Wire feed speed (m/min) & ER5087 & 1.05 \\
Travel speed (mm/min) & & 300 \\
Ce-W electrode diameter $(\mathrm{mm})$ & 3.2 \\
Arc length (mm) & 5 \\
\hline
\end{tabular}




\begin{tabular}{lc}
\hline Flow rate of $99.99 \%$ argon shielding gas (L/min) & 18 \\
Interval time between two layers (s) & 60 \\
Number of layers & 70 \\
\hline
\end{tabular}

\subsection{Heat treatment process}

Thin wall components were processed in three conditions: as-deposited, post-deposition T4 and T6 heat-treated. The T4 and T6 heat treatment procedures contain two steps: solution treatment + natural/artificial aging in T4/T6 conditions. The sample was heated in muffle furnace from $30^{\circ} \mathrm{C}$ to $498^{\circ} \mathrm{C}$ by the rate of $300^{\circ} \mathrm{C} / \mathrm{h}$ and kept for $90 \mathrm{~min}$, and then quenched in cold water during solution treatment procedure. Natural aging was carried out at the room temperature for $48 \mathrm{~h}$. Artificial aging was conducted at $190^{\circ} \mathrm{C}$ for $6 \mathrm{~h}$ at $300^{\circ} \mathrm{C} / \mathrm{h}$ heating rate from $30^{\circ} \mathrm{C}$, and then followed with furnace cooling.

\subsection{Testing procedure}

The section of samples for testing is shown in Fig. 2a. The center part of thin wall component was selected as microstructure and micro hardness testing sample. The sections from the middle to each end were machined to be vertical and horizontal tensile specimens. In this paper, depositing and welding direction are regarded as vertical and horizontal direction, respectively. Fig. $2 \mathrm{~b}$ reveals the dimensions of tensile specimens.

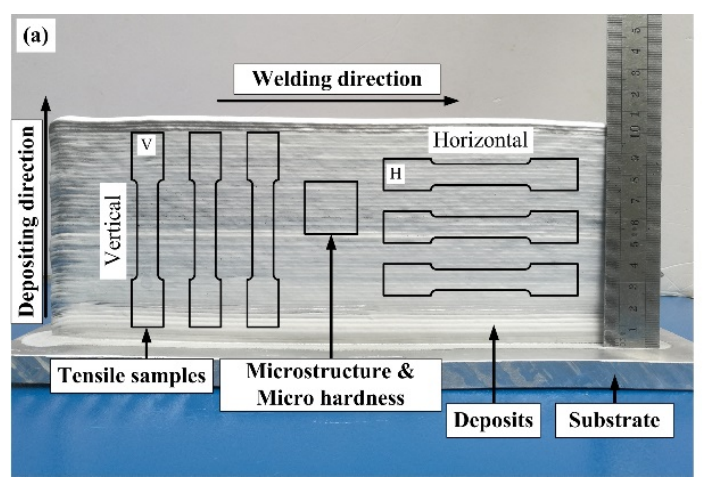

(b)

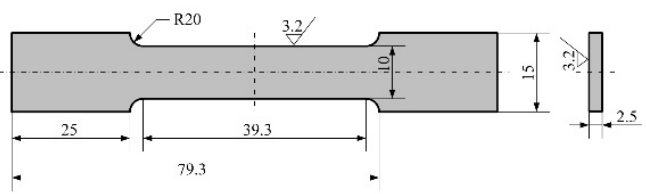

Fig. 2. (a) Sampling section of thin wall component; (b) dimension of tensile specimen

The specimens of longitudinal section for microstructure and micro hardness test were gradually ground with 400, 800, 1200, 1500 and 2000 abrasive paper, then polished with $3.5 \mu \mathrm{m}$ diamond paste. X-ray diffraction (XRD) tests were carried out with X-ray diffractometer (D/Max2200pc) to detect the interior phase. Scanning electron microscopy (SEM) (Camscan-3400) and optical microscopy (OM) (LEICA DM4000) were applied for microstructure investigation. Energy 
dispersive spectrometry (EDS) was adopted for composition analysis. Vickers (FM800) was employed for micro hardness tests with $1.96 \mathrm{~N}$ load for $15 \mathrm{~s}$. Thirty points with $0.5 \mathrm{~mm}$ interval were tested along depositing direction, which starts at 50mm distance from the bottom of deposits. XRD, SEM with EDS and micro hardness tests were accomplished firstly. Etching was conducted before OM tests. Tensile property tests were performed by a universal testing machine (SANS 5504) with $1.5 \mathrm{~mm} / \mathrm{min}$ loading rate at room temperature. Fracture was observed with SEM.

\section{Results and discussion}

\subsection{Microstructure}

The microstructure of the WAAM 2024 alloys in different conditions is shown in Fig. 3. Influenced by the layer-by-layer depositing mode, the microstructure presents distinct layer characteristics. As shown in Fig. 3a, Fig. 3d and Fig. 3g, each layer contains inner-layer region and inter-layer region. Inter-layer is the region containing remelted top area of former layer and the bottom area of current deposited layer. The microstructure in different regions and conditions shows diverse morphology. In inner-layer region with as-deposited condition, the microstructure mainly consists of equiaxed dendrites (ED), equiaxed non-dendrites (END), and columnar dendrites (CD), as shown in Fig. 3b. The columnar dendrites present belt-like distributing characteristics. The mixed equiaxed dendrites and equiaxed non-dendrites mainly spread over the area between columnar dendrite belts or other areas. In as-deposited inter-layer region, only equiaxed dendrites and equiaxed non-dendrites with non-uniformly distributing characteristics can be found, as shown in Fig. 3c. After heat treatment, the layer distributing characteristics still can be found, however, the microstructure changes compared with the one in as-deposited condition. It can be seen from Fig. 3d to Fig. 3i that with the effect of heat treatment the dendrite morphology disappears. The microstructure of 2024 deposits with T4 and T6 heat-treated condition shows the same feature: equiaxed non-dendrites and belt-like columnar non-dendrites (CND) with alternant distributing characteristics in inner-layer region (Fig. 3e and Fig. 3h); equiaxed non-dendrites in inter-layer region (Fig. 3f and Fig. 3i). 

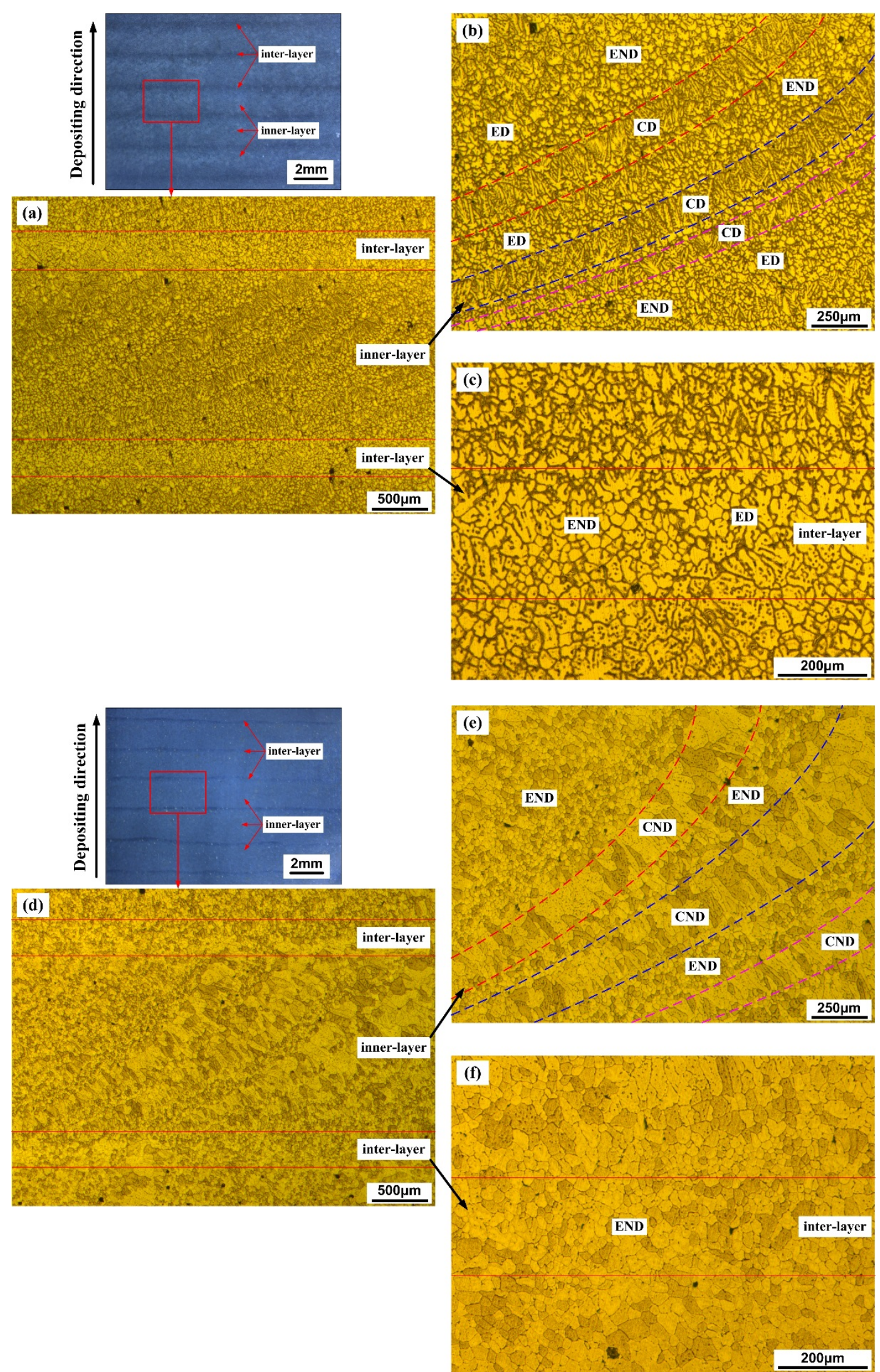


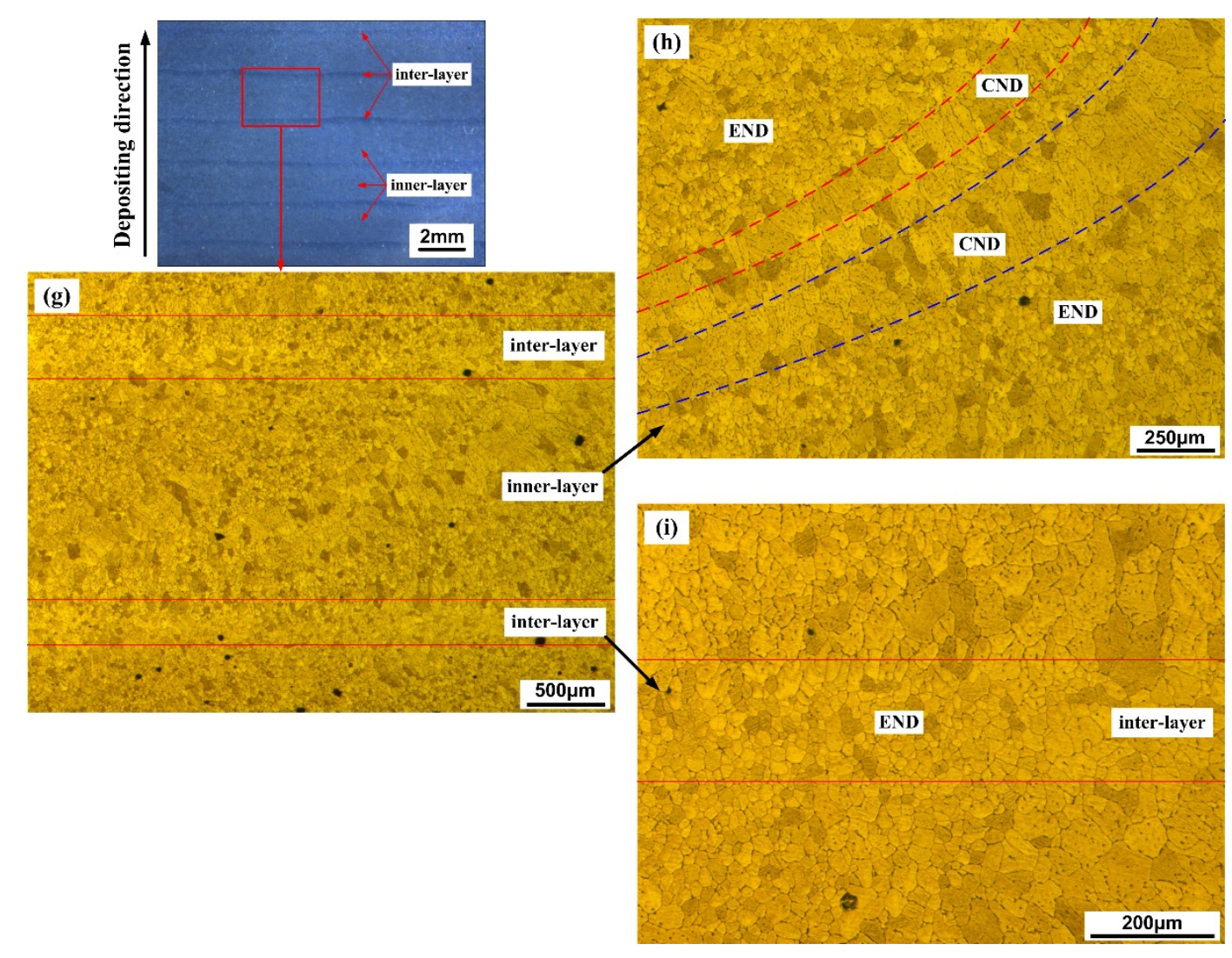

Fig. 3. Optical micrographs of 2024 deposits: (a) whole region, (b) inner-layer, (c) inter-layer in asdeposited condition; (d) whole region, (e) inner-layer, (f) inter-layer in T4 condition; (g) whole region, (h) inner-layer, (i) inter-layer in T6 condition

$\mathrm{XRD}$ results of the specimens are presented in Fig. 4. As shown in Fig. 4a, $\alpha$-Al, $\theta$ phase $\left(\mathrm{Al}_{2} \mathrm{Cu}\right)$ and $S$ phase $\left(\mathrm{Al}_{2} \mathrm{CuMg}\right)$ are detected in as-deposited WAAM 2024 alloy specimen. According to the solidification pathways of Al-Cu-Mg alloys with Scheil analysis [17], nonisothermal eutectic reaction ( $L \rightarrow L+\alpha \rightarrow L+\alpha+\theta \rightarrow \alpha+\theta+S$ ) occurs during the solidification process of 2024 deposits, leaving $\alpha$-Al, $\theta$ phase and $S$ phase inside. After heat treatment (both T4 and T6), $S$ phase cannot be pointed out, and only $\alpha$-Al and $\theta$ phase exist in the 2024 deposits, as presented in Fig. 4b and Fig. 4c. 

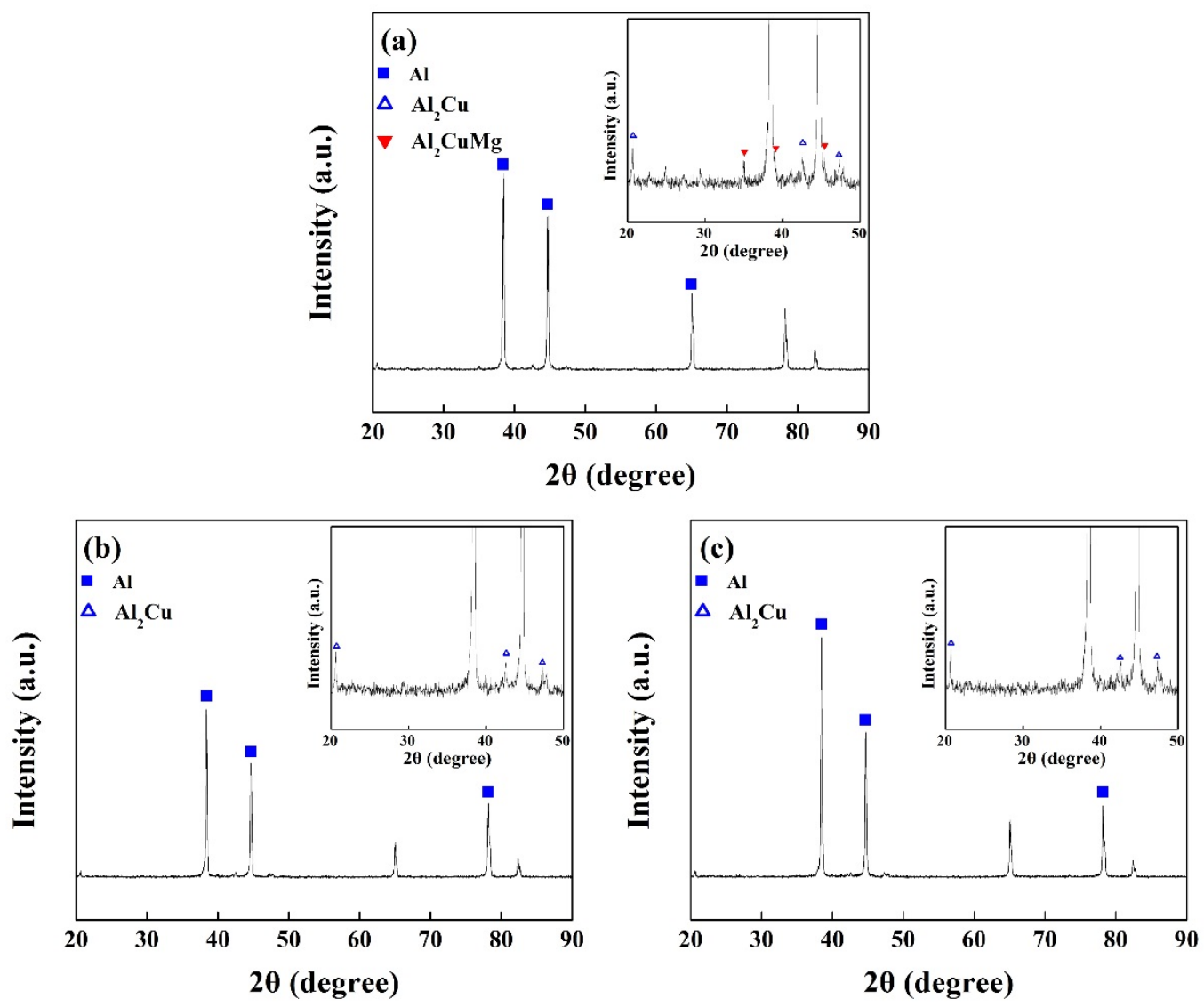

Fig. 4. XRD results of WAAM 2024 alloys (a) as-deposited; (b) T4 heat-treated; (c) T6 heat-treated

The SEM images attached with EDS results are shown in Fig. 5. SEM results in different regions are investigated due to the different microstructure morphology in inner-layer and interlayer. It can be seen from Fig. 5a to Fig. 5c, no difference of the second phase distributing characteristics can be found between inner-layer region and inter-layer region in as-deposited WAAM 2024 alloy. The white particles mainly net-likely distribute along the boundary or punctiformly scatter in interior of the grains. Combined with the EDS results, the bright white particle is identified to be $\theta$ phase, and the dark white one is $S$ phase. The $S$ phases distribute along the grain boundary, and $\theta$ phases disperse in the junction of the grain boundary or in the intra-grains. After heat treatment, the second phase and its distributing characteristics change. Obvious layereddivision feature of the particles can be found in T4 and T6 heat-treated deposits, as shown in Fig. 5d and Fig. 5g. In inner-layer region, a large number of second phase particles present dispersive and discontinuous distributing characteristics (Fig. 5e and Fig. 5h). In inter-layer region (Fig. $5 \mathrm{f}$ and Fig. 5i), the second phase particles also appear dispersively, however, their number is much smaller than that in inner-layer region. The attached EDS results reveal the particle is $\mathrm{Al}-\mathrm{Cu}$ eutectic $(\alpha-\mathrm{Al}$ and $\theta$ phase) both in inner-layer and inter-layer region of heat-treated (T4 and T6) WAAM 2024 alloys. 
In addition, a small number of dispersive pores can be found in as-deposited WAAM 2024 alloy (Fig. 5a), most of which mainly distributed in the upper zone of inner-layer region or slightly in inter-layer region. As the solubility of hydrogen in solid aluminum is lower than that in liquid aluminum [18], supersaturated hydrogen will be rejected during solidification. The hydrogen floating up and having no time for escaping will gather and form pores. Pores in the remelted top area of each layer will floating up again in next layer depositing process. When applying heat treatment to the deposits, the hydrogen pores may get together and grow up, leaving belt-like pores in inner-layer region.

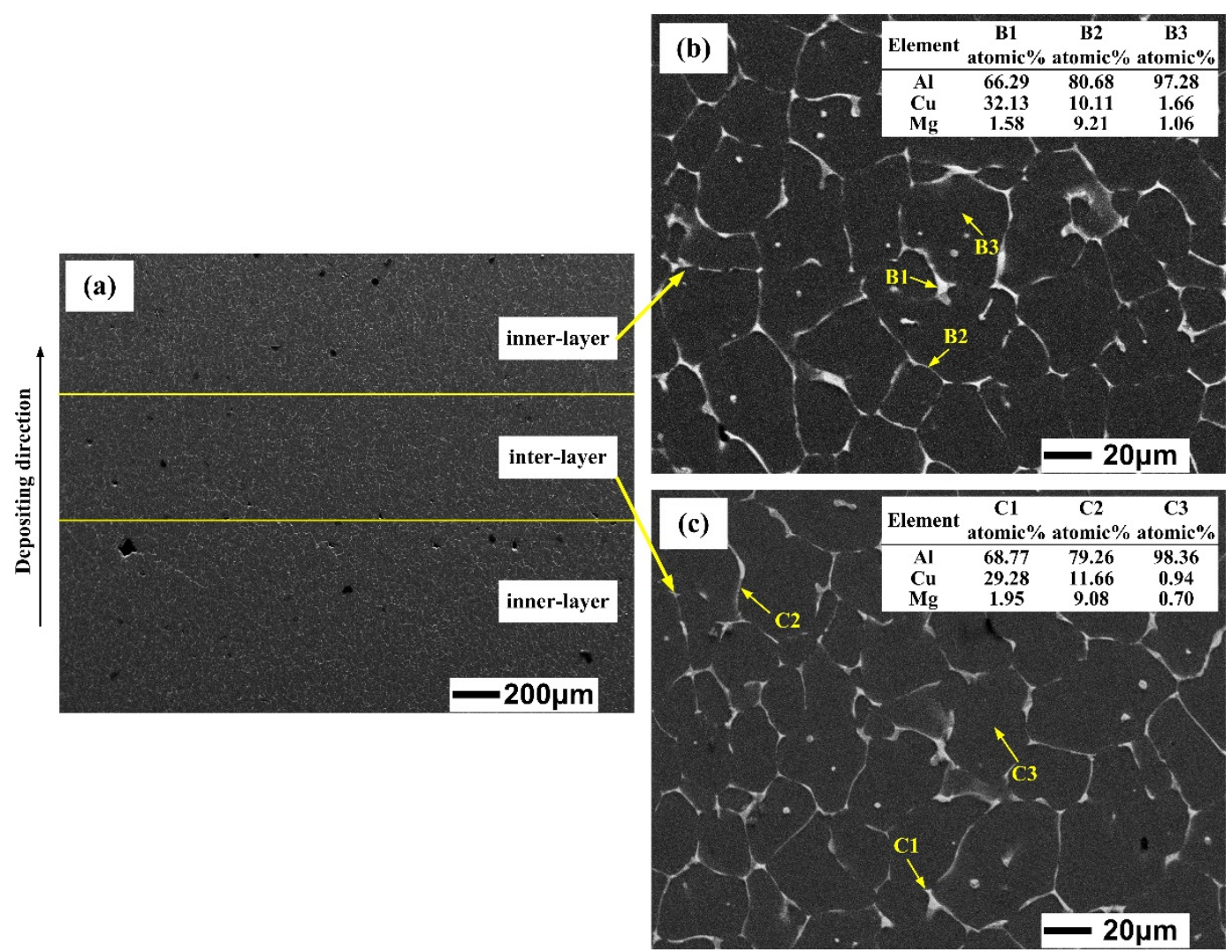



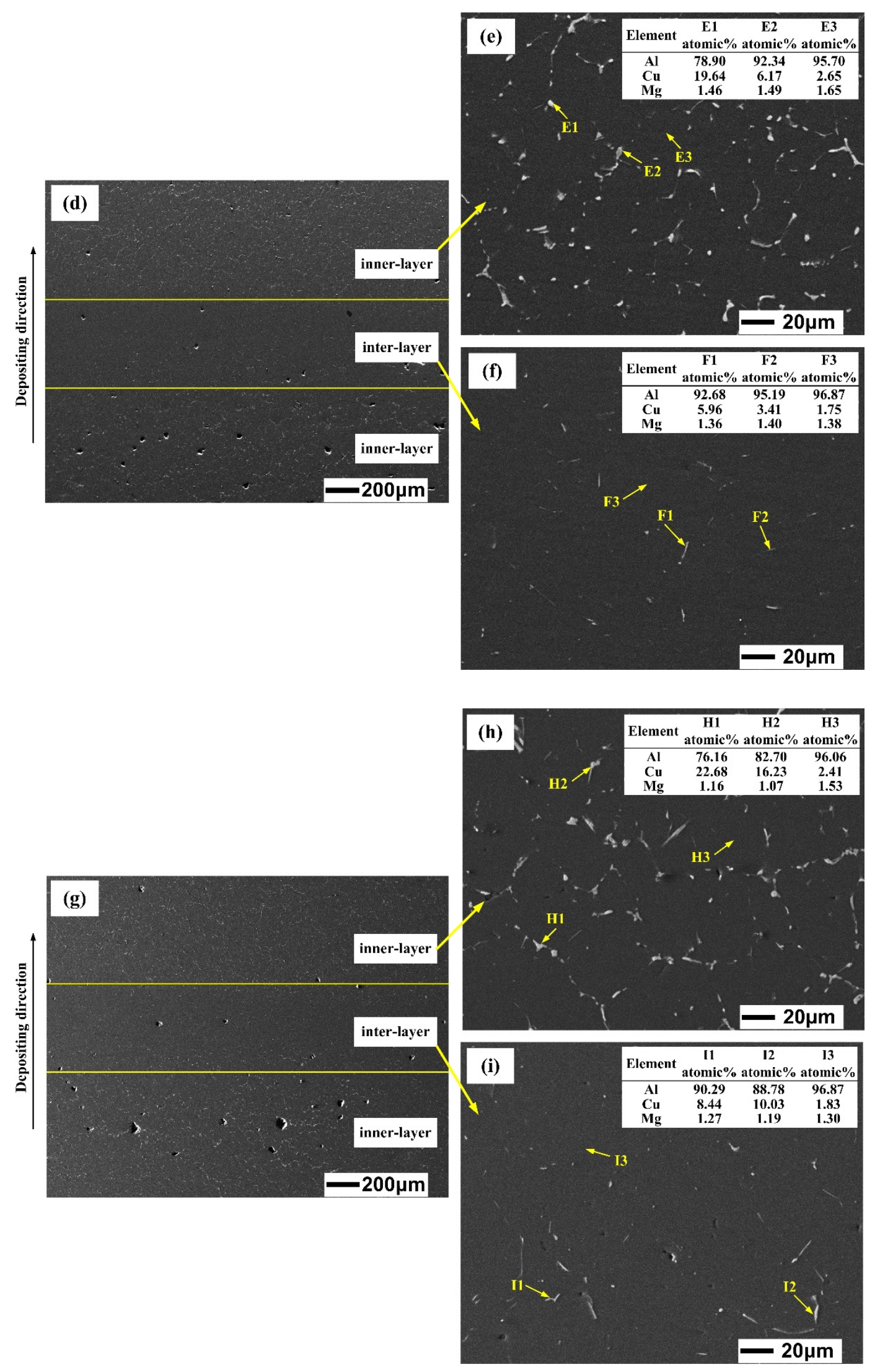

Fig. 5. SEM images with EDS results of WAAM 2024 alloys: (a) whole region, (b) inner-layer, (c) inter-layer in as-deposited condition; (d) whole region, (e) inner-layer, (f) inter-layer in T4 condition; (g) whole region, (h) inner-layer, (i) inter-layer in T6 condition 


\subsection{Micro hardness}

Fig. 6 reveals the averaged micro hardness value of these WAAM 2024 alloys in different conditions. The hardness value is $96 \mathrm{HV}$ in as-deposited condition, while, $138 \mathrm{HV}$ in T4 condition and $146 \mathrm{HV}$ in T6 condition. In comparison to the hardness value of as-deposited alloy, it is increased by $44 \%$ and $52 \%$ with $\mathrm{T} 4$ and $\mathrm{T} 6$ heat treatment, respectively. In addition, the hardness value after solution + natural/artificial aging heat treatment can exceed the one of AA2024-T4 plate (125 HV). It can be concluded that the heat treatment process can significantly increase micro hardness of WAAM 2024 alloy. The distribution of micro hardness value along vertical direction in these samples is shown in Fig. 7. Stationary distributing pattern of the hardness in as-deposited condition can be observed. However, after heat treatment the difference of micro hardness value increase, indicating the mechanical properties become inhomogeneous. This phenomenon is in accordance with the SEM results. Due to the different distributing characteristics of the second phase particles and pores in inter-layer and inner-layer region after heat treatment, the micro hardness shows relatively large difference. In as-deposited condition the difference of the second phase and pores distribution between inter-layer and inner-layer region is not obvious, thus, the micro hardness is much more consistent.

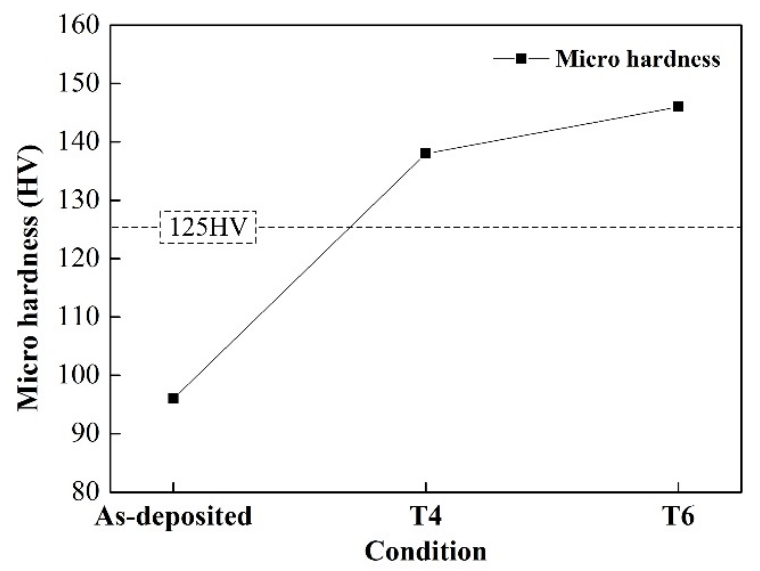

Fig. 6. Averaged micro hardness of WAAM 2024 alloys in different conditions 


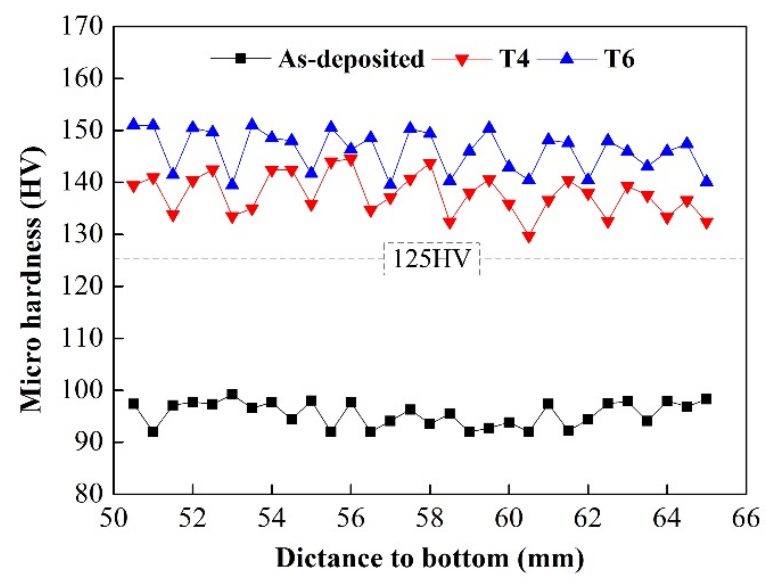

Fig. 7. Micro hardness distribution of WAAM 2024 alloys in different conditions

\subsection{Tensile properties}

The ultimate tensile strength (UTS), yield strength (YS) and elongation results are shown in Fig. 8. The tensile properties of as-deposited WAAM 2024 alloy present isotropic characteristics, with only $7 \mathrm{MPa}$ of UTS, $2 \mathrm{MPa}$ of YS and $0.4 \%$ of elongation lower in vertical direction than that in horizontal direction (UTS: $284 \mathrm{MPa}$, YS: $177 \mathrm{MPa}$, Elongation: 6\%), which are lower than the properties of AA2024-T4 plate (UTS: $470 \mathrm{MPa}$, YS: $325 \mathrm{MPa}$, Elongation: 19\%). After heat treatment, the strength and elongation in horizontal direction increase significantly, however, the elongation in vertical direction decreases. The UTS, YS and elongation in horizontal direction are $458 \mathrm{MPa}, 310 \mathrm{MPa}$ and $12.7 \%$ in T4 condition, respectively, and $470 \mathrm{MPa}, 374 \mathrm{MPa}$, and $8.2 \%$ in T6 condition. The strength in vertical direction also increases, but $63 \mathrm{MPa}$ and $60 \mathrm{MPa}$ of UTS, 16 MPa and $22 \mathrm{MPa}$ of YS lower than the one in horizontal direction, respectively in T4 and T6 condition. The elongation in vertical direction decreases to 5\% after T4 heat treatment, and $2.1 \%$ after T6 heat treatment. The tensile properties of post heat-treated WAAM 2024 alloy present anisotropic characteristics. After heat treatment, the strength properties nearly reach the applying level, while, the elongations are still lower than the one of AA2024-T4 plate. 


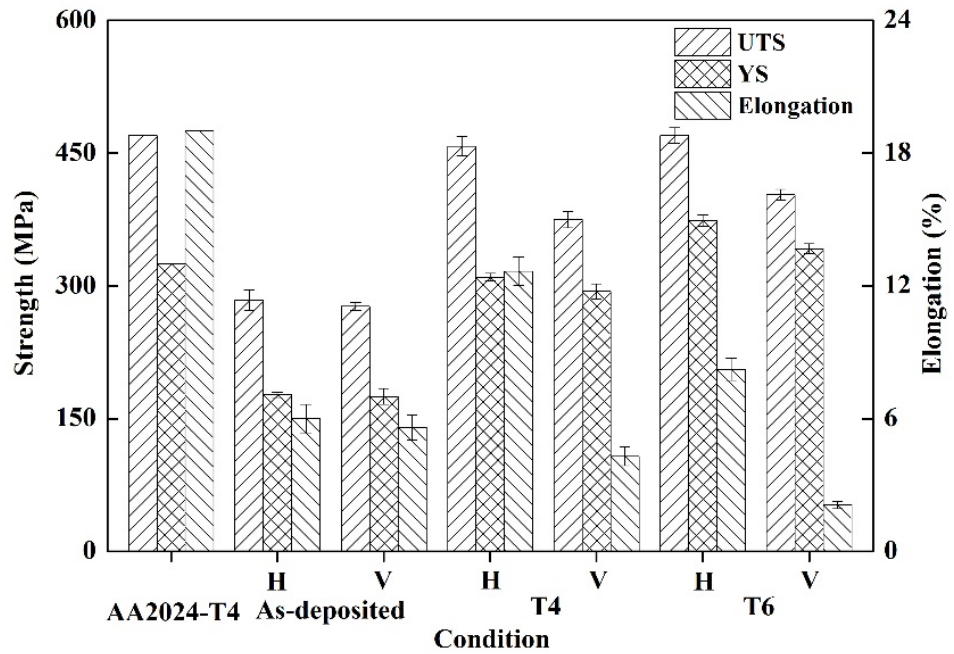

Fig. 8. Tensile properties of WAAM 2024 alloy components

For as-deposited WAAM 2xxx aluminum alloy, as described by Bai et al. [15], the precipitation strengthening effect is negligible, making the tensile properties lower than conventional AA2024T4 plate. After solution treatment + aging process, the precipitation strengthening effect is improved to a large degree, resulting in strength properties enhancement. The anisotropic characteristic of the tensile properties in heat-treated WAAM 2024 alloys is related to the microstructure results. For the tensile test specimen along vertical direction, each layer is perpendicular to the tensile force direction (Fig. 9). The characteristics of being rich in pores in inner-layer region, as described above, make this area having smaller loading area and lower bearing capacity and easier to fracture. For the one along horizontal direction, each layer is in parallel with the tensile force direction (Fig. 9). The weaken effect of pores is limited. Therefore, the properties of heat-treated WAAM 2024 alloy in horizontal direction are superior to that in vertical direction. The side view results of fracture samples are presented in Fig. 10. It can be seen from the horizontal samples that fracture propagates across each layers (Fig. 10a, Fig. 10c and Fig. 10e). For as-deposited vertical tensile sample, fracture occurs in the boundary between inner-layer and inter-layer (Fig. 10b). While, the fracture takes place in inner-layer region after heat treatment (Fig. 10d and Fig. 10f). 


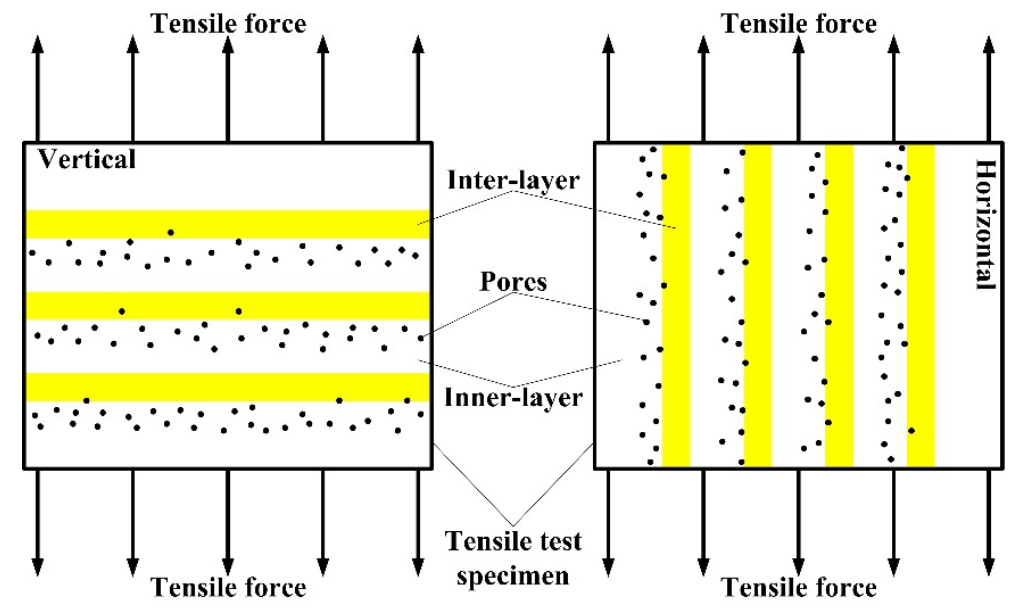

Fig. 9. Schematic diagram of tensile test
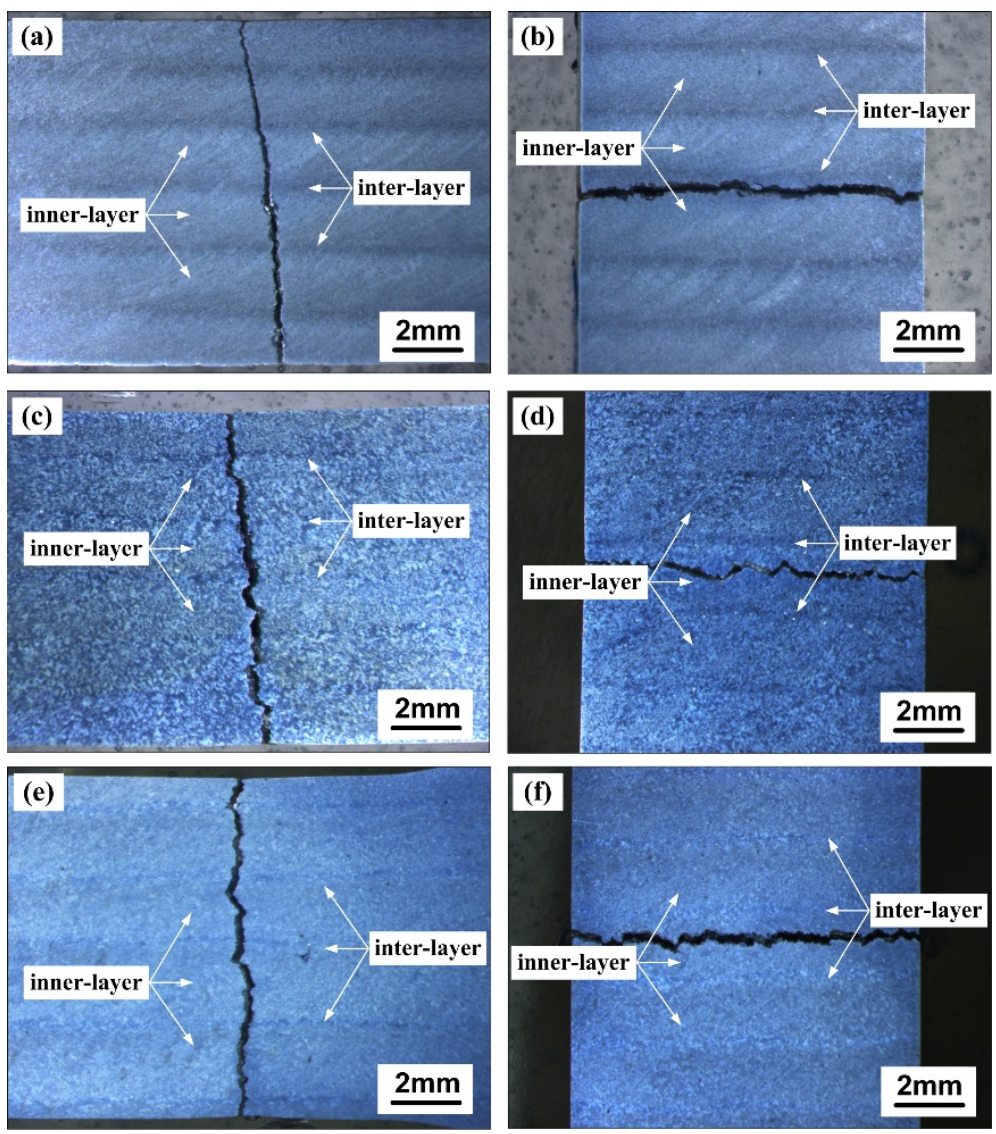

Fig. 10. The side view result of the tensile samples: (a) as-deposited, (c) T4 and (e) T6 in horizontal direction; (b) as-deposited, (d) T4 and (f) T6 in vertical direction

\subsection{Fracture morphology}

The fracture feature investigated by SEM for the 2024 deposits in T4 condition is shown in Fig. 11. It can be seen that obvious belt-like pores divide the horizontal fracture surface into two areas, as shown in Fig. 11a. For the fracture along vertical direction, a large number of pores can be found uniformly scattering in the whole surface (Fig. 11b). Combined with the above analysis, when tensile 
force is applied to specimen in vertical direction, the fracture easily occurs in the region being rich in belt-like pores, leaving a large number of pores in the vertical fracture surface (Fig. 11b).
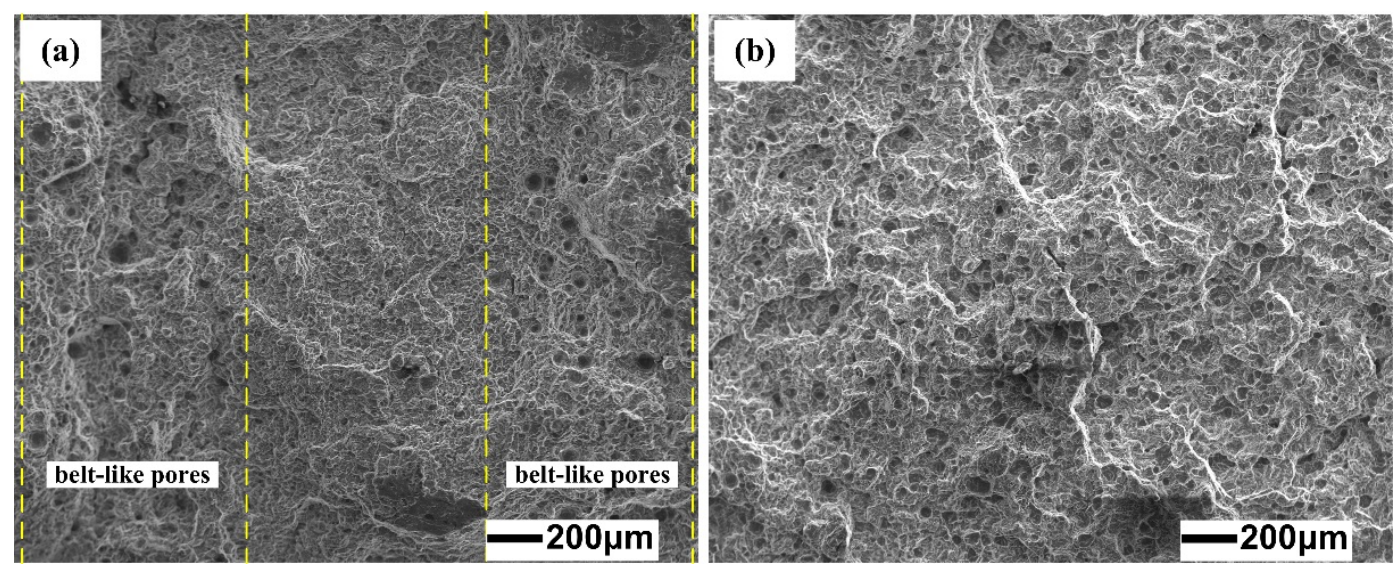

Fig.11. Fracture feature for WAAM 2024 alloy in T4 condition: (a) in horizontal direction, (b) in vertical direction

The appearance of micro fracture surfaces for these WAAM 2024 alloys in different conditions and directions are shown in Fig. 12. For as-deposited tensile specimen, the fracture presents similar feature. Intergranular fracture is the dominant fracture mode both in horizontal and vertical direction, with a small number of pores and second cracks on the surface, as shown in Fig. 12a and Fig. 12b. Dimples also can be found in as-deposited condition. After heat treatment, the major fracture pattern in horizontal tensile specimen is intergranular fracture accompanied with transgranular fracture, with some dimples inside (Fig. 12c and Fig. 12e). Pores of the heat-treated horizontal fracture present belt-like characteristics. However, in vertical specimen, no dimples can be identified, and the fracture presents intergranular fracture, with plenty of pores uniformly distributing on the surface (Fig. 12d and Fig. 12f). 

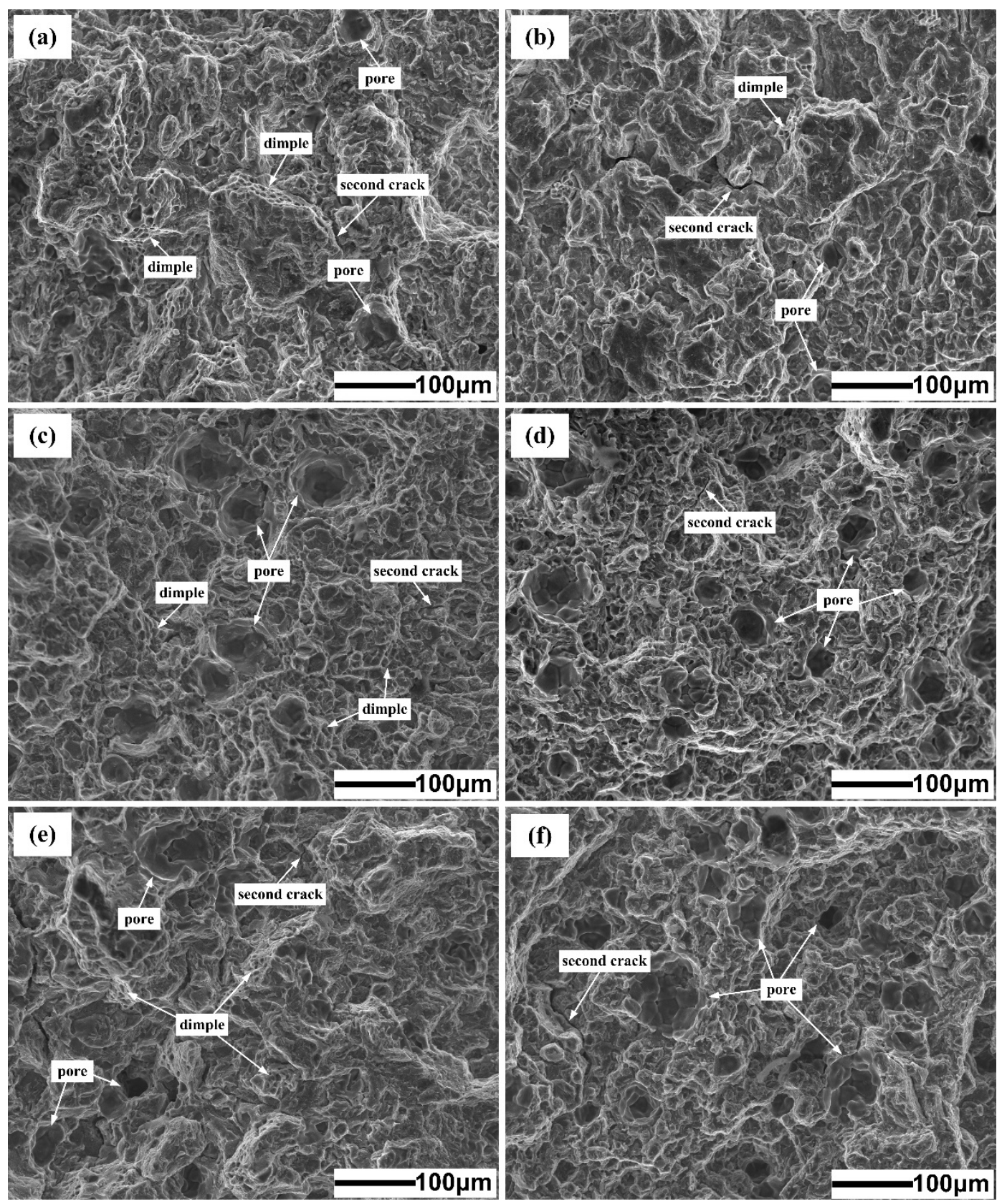

Fig.12. Fracture feature for WAAM 2024 alloys: (a) as-deposited, (c) T4 and (e) T6 in horizontal direction; (b) as-deposited, (d) T4 and (f) T6 in vertical direction

\section{Conclusions}

In this study, WAAM 2024 aluminum alloys were produced by adjusting the feed speed of ER2319 and ER5087 wires, and heat treatments (solution + natural/artificial aging) were conducted to process the components. The microstructure and mechanical properties of as-deposited and post heat-treated samples were investigated. The conclusions can be drawn as following. 
(1) The microstructure of as-deposited WAAM 2024 alloy mainly consisted of equiaxed (non-)dendrites and columnar dendrites in inner-layer region, and equiaxed (non-)dendrites in interlayer region. The dentrite morphology disappeared after heat treatment.

(2) In as-deposited WAAM 2024 alloy, $\alpha$-Al, $\theta$ phase and $S$ phase distributed in the whole region. After heat treatment, plenty of $\mathrm{Al}-\mathrm{Cu}$ eutectics ( $\alpha-\mathrm{Al}$ and $\theta$ phase) discontinuously scattered on aluminum matrix in inner-layer. The number of second phase particles in inter-layer was little.

(3) The averaged micro hardness was 95 HV in as-deposited WAAM 2024 alloy, while, it can be enhanced to $138 \mathrm{HV}$ and $146 \mathrm{HV}$ with T4 and T6 heat treatment, respectively.

(4) The tensile properties presented isotropic characteristics in as-deposited WAAM 2024 alloy, and anisotropic characteristics after heat treatment. The strength and elongation along horizontal direction can be improved by heat treatment, while, elongation along vertical direction decreased.

(5) Heat treatments can significantly affect the microstructure and mechanical properties of WAAM 2024 alloy. Eliminating the porosity and reducing the property anisotropy are also should be done for further research and application.

\section{Acknowledgements}

This work is supported by the National Natural Science Foundation of China (grant numbers 51675031), the Academic Excellence Foundation of BUAA for PhD Students, the Beijing Municipal Natural Science Foundation (grant numbers 3182020), the Fundamental Research Funds for the Central Universities (grant numbers YWF-18-BJ-J-244).

\section{References}

[1] Herzog D, Seyda V, Wycisk E, Emmelmann C. Additive manufacturing of metals. Acta Materialia 2016; 117: 371-392, https://dx.doi.org/10.1016/j.actamat.2016.07.019.

[2] Wang F, Williams S, Colegrove P, Antonysamy A. Microstructure and mechanical properties of wire and arc additive manufactured Ti-6Al-4V. Metallurgical and Materials Transactions A 2013; 44: 968-977, https://dx.doi.org/10.1007/s11661-012-1444-6.

[3] Martina F, Mehnen J, Williams S, Colegrove P, Wang F. Investigation of the benefits of plasma deposition for the additive layer manufacture of Ti-6Al-4V. Journal of Materials Processing Technology 2012; 212: 1377-1386, https:// doi.org/10.1016/j.jmatprotec.2012.02.002. 
[4] Williams S, Martina F, Addison A, Ding J, Pardal G, Colegrove P. Wire + arc additive manufacturing. Journal of Materials Science and Technology 2016; 32: 641-647, https://doi.org/10.1179/1743284715Y.0000000073.

[5] Bai J, Yang C, Lin S, Dong B, Fan C. Mechanical properties of 2219-Al components produced by additive manufacturing with TIG. International Journal of Advanced Manufacturing Technology 2016; 86: 479-485, https://doi.org/10.1007/s00170-015-8168-x.

[6] Cong B, Sun H, Peng P, Qi B, Zhao G. Porosity control of wire + arc additively manufactured Al-6.3Cu alloy deposition using AC-GTAW process. Rare Metal Materials and Engineering 2017; 46: 1359-1364.

[7] Cong B, Ding J, Williams S. Effect of arc mode in cold metal transfer process on porosity of additively manufactured $\mathrm{Al}-6.3 \% \mathrm{Cu}$ alloy. International Journal of Advanced Manufacturing Technology 2015; 76: 1593-1606, https://doi.org/10.1007/s00170-014-6346-x.

[8] Cong B, Qi Z, Qi B, Sun H, Zhao G, Ding J. A comparative study of additively manufactured thin wall and block structure with $\mathrm{Al}-6.3 \% \mathrm{Cu}$ alloy using cold metal transfer process. Applied Sciences Basel 2017; 7: 275, https://doi.org/10.3390/app7030275.

[9] Gu J, Ding J, Williams S, Gu H, Bai J, Zhai Y, Ma P. The strengthening effect of inter layer cold working and post-deposition heat treatment on the additively manufactured $\mathrm{Al}-6.3 \mathrm{Cu}$ alloy. Materials Science and Engineering A 2016; 651: 18-26, https://doi.org/10.1016/j.msea.2015.10.101

[10] Gu J, Ding J, Williams S, Gu H, Ma P, Zhai Y. The effect of inter-layer cold working and postdeposition heat treatment on porosity in additively manufactured aluminum alloys. Journal of Materials $\quad$ Processing $\quad$ Technology 2016; 26-34, https://dx.doi.org/10.1016/j.jmatprotec.2015.11.006.

[11] Qi Z, Cong B, Qi B, Sun H, Zhao G, Ding J. Microstructure and mechanical properties of double - wire + arc additively manufactured Al-Cu-Mg alloys. Journal of Materials Processing Technology 2018; 255: 347-353, https://doi.org/10.1016/j.jmatprotec.2017.12.019.

[12] Lin Y, Wang D, Wang M, Zhang Y, He Y. Effect of different pre- and post-weld heat treatments on microstructures and mechanical properties of variable polarity TIG welded AA2219 joints. Science and Technology of Welding and Joining 2016;21:234-241, https://doi.org/10.1179/1362171815Y.0000000087 
[13] Pabandi H, Jashnani H, Paidar M. Effect of precipitation hardening heat treatment on mechanical and microstructure features of dissimilar friction stir welded AA2024-T6 and AA6061-T6 alloys. Journal of Manufacturing Processes 2018; 31: 214-220, https://doi.org/10.1016/j.jmapro.2017.11.019.

[14] Hu Z, Yuan S, Wang X, Liu G, Huang Y. Effect of post-weld heat treatment on the microstructure and plastic deformation behavior of friction stir welded 2024. Materials and Design 2011; 32: 5055-5060, https://doi.org/10.1016/j.matdes.2011.05.035.

[15] Bai J, Fan C, Lin S, Yang C, Dong B. Mechanical properties and fracture behaviors of GTAadditive manufactured 2219-Al after an especial heat treatment. Journal of Materials Engineering and Performance 2017; 26: 1808-1816, https://doi.org/10.1007/s11665-017-26275.

[16] Qi Z, Cong B, Qi B, Zhao G, Ding J. Properties of wire + arc additively manufactured 2024 aluminum alloy with different solution treatment temperature. Materials Letters 2018; 230: 275-278,https://doi.org/10.1016/j.matlet.2018.07.144.

[17] Pickin C, Williams S, Prangnell P, Robson J, Lunt M. Control of weld composition when welding high strength aluminum alloy using the tandem process. Science and Technology of $\begin{array}{lllll}\text { Welding } & \text { and } & \text { Joining } & \text { 734-739, }\end{array}$ https://doi.org/10.1179/136217110X12785889549660.

[18] Boeira A, Ferreira I, Garcia A. Alloy composition and metal/mold heat transfer efficiency affecting inverse segregation and porosity of as-cast Al-Cu alloys. Materials and Design 2009; 30: 2090-2098, https://doi.org/10.1016/j.matdes.2008.08.032. 
2019-03-09

\section{Microstructure and mechanical}

properties of wire + arc additively

manufactured 2024 aluminum alloy

components: As-deposited and post heat-treated

Qi, Zewu

Elsevier

Qi Z, Qi B, Cong B, et al., (2019) Microstructure and mechanical properties of wire + arc additively manufactured 2024 aluminum alloy components: As-deposited and post heat-treated.

Journal of Manufacturing Processes, Volume 40, April 2019, pp. 27-36

https://doi.org/10.1016/j.jmapro.2019.03.003

Downloaded from Cranfield Library Services E-Repository 